\title{
Compasión y salud
}

\author{
ALEXANDER JIMÉNEZ, MANUEL TRIANA y JIMMY WASHBURN
}

Escuela de Filosofía, Universidad de Costa Rica

\author{
Quiero ayudar al bueno a ser su poquillo de malo \\ y me urge estar sentado \\ a la diestra del zurdo, y responder al mudo, \\ tratando de serle útil en \\ lo que puedo, y también quiero muchísimo \\ lavarle al cojo su pie, \\ y ayudarle a dormir al tuerto próximo.
}

(César Vallejo)

REsumen. La compasión es una actitud que ha sido objeto de ataques, que ha sido catalogada como un egoísmo encubierto o bien como una pose lastimera que poco o nada contribuye para el auxilio debido a las personas en desgracia. Pero, es precisamente el despojo y los daños que las personas sufren los que llevan a pensar cómo es posible «salvar» esas vidas, no permitir que se pierdan y afirmar que la vida vale la pena. En virtud de ello, la compasión o misericordia ha de ser repensada con miras a concederle el lugar adecuado dentro del mundo sanitario. Su significado ético pasa, por tanto, por una elucidación racional -qué es-y los rasgos que la caracterizan -fragilidad, desgracia, reconocimiento, solidaridad-. El símbolo da que pensar, y la reflexión ética, en este caso, se nutre de la parábola del Buen Samaritano.

\section{INTRODUCCIÓN}

El señor $\mathrm{N}^{1}{ }^{1}$, recién hospedado en un hogar de ancianos costarricense, con noventa años de edad, sufre de cáncer pulmonar y de enfermedad enfisematosa con requerimientos de oxigenoterapia. Ante
Abstract. Compassion is an attitude that have been attacked and qualified as an undercover selfishness or as a injurious pose. None of them contributes to help the unfortunates. Even more, spoliation and harms suffered by persons, take to figure out how to «save» those lives, not allowed to loose them and assess life is worth it. Owing to this, compassion or mercy has to be thought in order to get the right place in the health care system. Its ethical meaning, therefore, goes through the rational explanation -what it is- and it features - fragility, misfortune, recognition, solidarity-. Symbols ought to think, and ethical thought is nurtured by the Good Samaritan text.

una crisis respiratoria es llevado de emergencia al hospital, mas allí no es atendido por ser un «abuelo» que estaba pronto a morir. Bastaba esperar. Ninguna autoridad intervino, la disposición es clandestina. Una situación cotidiana, probablemente, pero que obliga a la reflexión acerca de 
las percepciones de la vida y la muerte que pueden justificar la omisión y disponer de la existencia de cualquier persona. El señor N. no fue atendido por estar sin familia y por su edad. El atropello sufrido, por lo tanto, es la ocasión de rescate y afirmación de la dignidad humana y de los compromisos que de ella se derivan.

Finitud y compasión, sufrimiento y solidaridad. El dolor humano y los abusos se encuentran por doquier. Son un escándalo para la conciencia. La comprensión de la finitud humana y las respuestas éticas que se aparejan a ella es el tema que aquí queremos bosquejar. De manera particular, queremos comprender el lugar de la compasión en ello.

La compasión es una actitud moral compleja: se ha dicho que es un sentimiento, una pasión, una virtud, un mandamiento, está más allá de la justicia; es una debilidad moral, una forma de egoísmo encubierto, una actitud femenil, según Spinoza, contraria a la «naturaleza» más racional de los hombres ${ }^{2}$. La discusión ha sido abundante y no está clausurada.

Además, su significación para las relaciones intersubjetivas no es la misma entre extraños, que es el caso de las relaciones clínicas, que entre cercanos. Aunque las respuestas compasivas pasan por un momento cognitivo - reconocimiento de la desgracia del otro-, pareciera ese momento insuficiente para justificarlas, una dificultad de la que somos conscientes.

Lo anterior se reafirma ante las apelaciones a la compasión para que la desgracia vivida cese. Pero ello es pedir la muerte, como lo han hecho Diane Pretty ${ }^{3}$, Karen Ann Quinlan ${ }^{4}$ y Ramón Sampedro ${ }^{5}$, vidas y dilemas muy publicitados. Resulta aquí contradictoria la compasión cuando ésta significa una afirmación de la vida, y más si esas personas están «condenadas» a vivir con deterioros irreversibles soportados y su sentido de la vida minado. En la práctica clínica, además, encontramos profesionales del cuidado, las enfermeras, quienes se entendieron a sí mismas, a partir de una repartición de oficios y saberes por género. Pareciera que los retos y respuestas pueden ser también asignados por género. La compasión y con ella el cuidado, parecieran propios de mujeres pero el buen samaritano lo desmiente. ¿Qué obliga a la compasión que no sea la condición de género?

Hospitales y clínicas reúnen a extraños y frágiles. Extrañeza y fragilidad son vivencias intensas de pacientes y usuarios de servicios de salud. La relación clínica puede tanto abonar a esa vulnerabilidad y agravar las sensaciones de dependencia y angustia, como bien ofrecer estrategias de compensación y un clima de interacción para un apoyo efectivo a quienes lo necesiten.

Algo de todo esto queremos hablar en esta ocasión.

\section{MUNDO DE LA VIDA, SUFRIMIENTO, MUNDO DE LA SALUD}

La reflexión ética vive una especial tensión entre la especulación teórica y la comprensión y valoración de las experiencias concretas. Hemos de evitar el divorcio entre conocimiento y experiencia (cf. López, 2000a, p. 59).

Estas tensiones operan, pues, como un ligamen entre dos mundos. El mundo de la vida alimenta la reflexión y ésta arroja luces sobre aquél. Este doble carácter de la ética se traduce en una pauta metodológica de la cual se quiere echar mano en esta ocasión. Vivencias y argumentaciones son los elementos que integran todo el saber ético, pero no basta su presencia, sino la comunicación en ambas direcciones que el filósofo establece. Las primeras exigen interpretación y para ello se requiere de criterios previos que garanticen su examen y comprensión, sin cometer deslices 
cognitivos que justifiquen indebidamente pautas prácticas.

En ese sentido, valdría decir que el mundo de la vida es no sólo un a priori de la reflexión, sino una trascendencia, puesto que siempre es mayor en correspondencia con la realidad a la que remite y de la cual el pensamiento no da suficiente razón ${ }^{6}$.

Una de las experiencias más significativas en el horizonte de nuestro mundo vital es la del sufrimiento o dolor. Y, sin embargo, los sistemas de pensamiento no siempre logran incorporarla y tornarla reflexiva. Entre los aspectos que estos sistemas filosóficos enfocan al tratar al ser humano, el sufrimiento y el dolor apenas podrían ser enumerados sin ocupar un lugar preponderante. Las más de las veces que es tomado en cuenta, aparece vinculado a lo que de alguna manera corroe la existencia humana, es decir, al mal. El dolor sería incluido entre los males, o como un daño que aqueja la vida humana.

¿Ha habido una antropología filosófica que tenga como punto de partida el dolor? No todos los grandes sistemas de pensamiento nos hablan propiamente de él, pues unido al daño, lo reducen a ser un elemento de ajuste de su arquitectónica. Pero el dolor ha motivado reflexiones.

Nuestra reflexión sobre el dolor y el sufrimiento atiende a la reacción ante los dolientes cuando sobrepasa la indiferencia, el temor, la angustia, y despierta la compasión. La compasión es un término polisémico, ya que apela a diversos rasgos como generosidad, altruismo, solidaridad, hospitalidad, acompañamiento, consuelo, entre otros. En la historia del pensamiento hay una tradición que arranca de Aristóteles, e incluye a filósofos como Hobbes, Descartes, Spinoza, Kant y Schopenhauer, para quienes la compasión es una forma de dolor causado ante un mal destructivo o penoso sufrido por alguien que no lo merece, y que pueda golpear a uno mismo o a un ser querido ${ }^{7}$. Asimismo hay otra tradición que arranca de los estoicos, y se continúa en Nietzsche, según la cual la compasión es una emoción que mantiene y continúa la emoción del dolor ajeno, por lo que debe ser rechazada ${ }^{8}$. Como podemos ver, existen dos interpretaciones que generan dificultad para un acuerdo ético al respecto de una misma experiencia. Lo anterior se refleja en que no se ha dado una misma estima de la compasión y tanto ha sido enaltecida como rebajada. Incluso significados de compasión que aquí indicamos, en otros sitios son asumidos como cuidados terapéuticos. Sin embargo, ciertos rasgos de esos cuidados llevan a pensar más en la compasión: sensibilidad a la vulnerabilidad del otro, inmediatez de las relaciones, la dependencia de los sujetos, la vulnerabilidad de unos y el auxilio de otros, la premura del tiempo, la cercanía luego de la extrañeza, la existencia humana gravada por la contingencia.

\section{COMPASIÓN Y BIOÉTICA}

En escritos bioéticos se encuentran indicaciones de la compasión como un principio (cf. OPS, 1990, p. 21) o como una virtud (Beauchamp y Childress, pp. 32-34), y se la liga con el principio de beneficencia. A menudo no se la menciona del todo. Hay quienes apelan a ella para tomar decisiones vitales como el cese de la vida de una persona en condición terminal o para la fertilización de mujeres deseosas de ser madres, y en éstas y otras situaciones puede ser tanto un apoyo o respaldo para las personas afectadas o bien puede ser simplemente un móvil que opera momentáneamente y matiza, según el examen de las circunstancias, decisiones y acciones. El esclarecimiento racional mira aquí a una distinción semántica que enriquezca las prácticas sanitarias en muchos sentidos, particularmente el ético. Robustecer las respuestas a situaciones de desgracia es imperativo y no puede, entonces, resumir- 
se al cuidado como tal, aunque la compasión pasa por él. Se trata de atender el sentido de arraigo y la legitimidad de la vida social dañadas. Ésta es tarea de la ética.

La compasión tiene implicaciones para el mundo sanitario. En el mundo de la salud hay una alta demanda de compromiso y responsabilidad. Nuestro análisis pasa por el relato del Buen Samaritano que, en pocas imágenes, muestra una serie de contenidos conjuntados a la misericordia ${ }^{9}$. Nos muestra la experiencia de la finitud y miseria humana, para la cual se requiere una actitud de resistencia contra las negaciones de la vida. Igualmente representa la compasión entre extraños: el acercamiento que no se establece por vinculaciones afectivas, sino por la desgracia que ha cobrado víctimas. Seguimos de esta forma el planteamiento de Ricoeur, según el cual «el símbolo da que pensar» y da qué pensar. Esto implica tanto el hecho de dar, como el motivo que suscita. También partimos de la idea aristotélica de que ante cualquier situación de infortunio, encontramos un atentado contra la vida que resulta inadmisible, "porque todos desean vivir», de donde se desprende el modo de delinear el talante ético y construir la intersubjetividad.

El lugar que se le conceda a la compasión en el terreno de la salud obliga a un examen justo, ya que cristaliza una pretensión de excelencia ${ }^{10}$ asociada con la disconformidad de vivir según unos mínimos, insuficientes ante la miseria humana y las exigencias de una convivencia humanizadora. El discurso bioético, sea una instancia de juicio, un saber o un procedimiento, invoca actitudes y apela a modelos de rectitud en los cuales es posible descubrir un lugar para la compasión. Y los contenidos de la compasión no se agotan en la bioética. Se colocan más allá de ella ${ }^{11}$. El mundo de la enfermería es un ámbito privilegiado para pensar esto.

\section{COMPASIÓN Y ÉTICA POR GÉNEROS}

Históricamente la compasión se ha asociado con la profesión enfermera. «Un bien mayor, propio de la enfermería, se identifica con la compasión. La compasión, una forma intensa de benevolencia, es un bien intrínseco a la virtud del cuidado en la práctica profesional enfermera» (Tuckett, p. 385). La profesión enfermera ha sido apuntalada con el cuidado y éste con la compasión, así como con un tipo de saber -aquel que no es médico aunque se parezca- y con el género femenino. No es casualidad que durante mucho tiempo la enfermería fuera una profesión estrictamente femenina.

Un siglo atrás, circulaban manuales de enfermería que dejaban en claro las exigencias éticas a las que debían someterse las mujeres para efectos de la atención a enfermos. Estas exigencias se amalgamaron con elementos vocacionales, con una cierta «sacramentalidad», y el conjunto resultante definía la profesión. Hoy en día las exigencias profesionales han dado un giro y la distinción entre el cuidado (de la enfermería) y la curación (objeto propio de la medicina) es de carácter epistemológico, gracias a una diferenciación de los objetos de estudio de las disciplinas biomédicas ${ }^{12}$. No obstante, sigue recayendo en la enfermería (mujeres) una mayor cuota y exigencia de trabajo: pasan más tiempo con sus pacientes, se ocupan de todas sus necesidades, actúan como enlace entre familiares, pacientes y médicos, ofrecen apoyo, traducen las disposiciones médicas y hacen los ajustes requeridos según sea el paciente.

El desempeño profesional requiere de la compasión y el cuidado parece exigir una virtud que no sea simplemente realizar bien el trabajo o dar un buen trato a sus pacientes. Las teorías feministas y los estudios históricos de la enfermería han arrojado evidencias sustantivas al respecto. 
Ligada la compasión al cuidado, se confirma una concepción ética antes mencionada, adecuada a las mujeres por ser más propia de su «naturaleza», mientras que una ética racional y dirigida al cumplimiento de principios, corresponde más a los varones. La enfermería se asocia con el género femenino y con una clasificación de la vida moral según rasgos inferiores y superiores ${ }^{13}$. La formación profesional enfermera, en un inicio, fue definida por médicos. Atención maternal, religiosidad, cuidados intuitivos, actitudes matizadas, la caridad debida a los enfermos, son algunos de los rasgos principales que la enfermera debía asumir. Ejecutante de procedimientos delegados por los médicos, ello no hacía mella en lo medular: su formación ética y moral. Ésta llega hasta su modo de vestir y conducirse y sobre todo implica unas altas cuotas de sacrificio personal en nombre de su profesión y enfermos. El cuidado enfermero es calificado de maternal, cariñoso y bondadoso, «... siendo algo incompatible con el temperamento varonil masculino» (Domínguez et al., p. 47).

La enfermería, entonces, se constituyó como una práctica polarizada con el actuar médico y recae en sus profesionales una actuación de tolerancia, complacencia y cooperación, con compromisos adicionales a los propios de la atención médica y quirúrgica, relativos a la atención de las necesidades psíquicas y afectivas de pacientes $\mathrm{y}$ familiares.

Los procedimientos y cuidados así como el funcionamiento de las instituciones son una garantía para el bienestar de cada paciente. Pero la atención a pacientes requiere de cualidades éticas que no todas las instituciones o personas poseen $\mathrm{o}$ desarrollan. Pareciera que el cuidado queda atrapado en una profesión y aunque cada día encontramos más personal enfermero masculino, no desaparece del todo la idea que la mujer enfermera es la más apta u obligada para ofrecerlo. Sin embargo, es necesario explorar «una vía más ancha para ejercer la responsabilidad moral» (López, 2000b, p. 63). La compasión, como el cuidado, no está suscrita a un género, ni son propios de una profesión, aunque históricamente así haya sido.

La compasión puede significar una altura moral producto de los compromisos con los desvalidos. Compromisos que significan devolver lo perdido, promover la existencia de la persona en desgracia como una vida buena. Así, las exigencias de que ha sido objeto la enfermera también dan muestras de un talante moral de amplio espectro por cuanto es capaz de asumir sus responsabilidades inmediatas y ser atenta a las necesidades del otro. ¿No es este rasgo moral de primer orden que nos coloca más allá del simple cumplimiento de la ley (mínimo ético)?

Aun cuando no se puede vivir ni recuperar la salud sin cuidados, no faltan valoraciones estrechas de estos últimos que pueden contribuir con una subestima del compromiso ético que encarnan. R. Hare en una colaboración acerca de los métodos de la bioética, apuntaba que una debilidad de la ética del cuidado es la ambigüedad del cuidado mismo, qué se ha de entender por ello, lo cual podría justificar actitudes muy contradictorias. "La conciliación de deberes o virtudes del cuidado y la justicia es un asunto difícil. Muchos de los tópicos más difíciles de la bioética giran sobre esta cuestión...» (Sumner \& Boyle, p. 28).

La reflexión sobre la compasión consiste en un examen de la relación entre el compasivo y el compadecido, y, por ende, debe verse en ambas direcciones: ¿qué ve e interpreta cada uno del otro? La definición de sí —quién soy— pasa por la definición del otro —quién es para sí y para míy por medio de ambas se establece la relación. La cuestión de si el origen de la ética se da en el cuidado de sí, bajo la perspectiva de la búsqueda de lo bueno, con y para los otros, o si es el encuentro con el rostro del otro, se definiría fácilmente en la perspectiva de la compasión por la 
segunda opción. Sin embargo, podría pensarse más que en una disyunción, en una dialéctica. Súmase a esto la dificultad para derivar de la desgracia del otro el deber de auxiliarlo. La indiferencia o la evasión son actitudes viables, pero queda la sensación de que la vida humana, la cual no se desarrolla monádicamente, no es tan humana con dichas actitudes. Pues así como el propio dolor y el sufrimiento generan un volver sobre sí, lo cual implica un encuentro consigo, también el encuentro con el otro doliente compadecido implica una atención y preocupación por su intimidad que permite un encuentro más cabal con él, lo cual tendría repercusiones en el encuentro del compasivo consigo mismo.

\section{EL BUEN SAMARITANO: RECONOCIMIENTO Y COMPASIÓN}

\section{1. ¿Compartir el dolor o afirmar la vida?}

Aunque la compasión puede remitir a la fe religiosa, en nuestro ensayo la compasión es entendida como actitud ética inervada por condiciones humanas originarias como la fragilidad y la finitud. Éstas provocan intuiciones morales a modo de respuestas: cuidados, acompañamiento, hospitalidad, generosidad, solidaridad, condolencia. Sin ellas estaríamos condenados al dolor y a la muerte en el primer instante de vulnerabilidad.

En virtud de esto, la compasión presupone la experiencia de la finitud como condición mortal universalmente comparti$d a$ aunque no siempre consciente, que moviliza las relaciones intersubjetivas.

El empeño reside no en compartir una condición común, sino en alejar la desgracia y la miseria para que no tengan lugar, para alejar la amenaza de muerte. Ésta es la esperanza que deriva de la compasión, en sentido trágico, no puesta en un deseo de salvación trascendental, sino en el valor de la vida humana, bien apreciable y justificante de todo esfuerzo para combatir la fatalidad. Estas acepciones distinguen la compasión del cuidado terapéutico. La compasión es a posteriori, sólo la hay cuando se está frente a la miseria del otro. Este punto confirma que la respuesta compasiva no es un deber que obligue a todos por igual o que se siga necesariamente de la constatación cognitiva del infortunio. Y nos confirma, asimismo, la compasión como una elaboración que cada uno lleva a cabo con miras a la convivencia.

El sufrimiento y la desgracia, o el desprecio del otro, tal y como lo analiza Honneth, no son inútiles por cuanto la solidaridad y la compasión afloran como la respuesta ética por las cuales la vida de las personas no pierde terreno, antes bien lo gana. La compasión reacciona al despojamiento sufrido, y se nutre del aprecio para con quien sufre pérdidas (de sí, de sentido, de los suyos, de su arraigo cultural).

El texto bíblico es muy sugerente en elementos relativos al valor de la compasión y su validez ética. Es un texto que habla de dilemas morales, de compromisos, de estilos de vida, de marginaciones y desprecio, de discernimiento y razón práctica.

\section{2. ¿De quién compadecerse?}

El texto comienza con una interrogante: no se sabe quién es el prójimo. Hay un obstáculo para su reconocimiento. La Parábola responde con la identificación de ese prójimo: aquel que está en desgracia y ha sido víctima de despojo, el que tiene su fragilidad expuesta y no puede solo con ella. Un paciente, grave o no, de cualquier hospital ha experimentado una disminución y hasta un desvalimiento que se agrava aún más cuando la atención no considera su situación particular y obedece más a disposiciones uniformadoras para el trato de pacientes. La miseria y la desgracia 
humanas no se presentan de manera tan evidente como aparece en el texto bíblico. Las encontramos como parte de la institucionalidad (servicios de salud cuya cobertura no es universal o cuyos recursos son precarios), asociadas con estructuras de poder (pobreza, discriminación) y con prácticas consolidadas en el mundo de la vida que han cobrado carta de naturalidad, como son los abusos domésticos cometidos contra mujeres, niños y adultos mayores.

Axel Honneth en su artículo Interés y Desprecio, desarrolla sugerencias de E. Bloch en torno a la afirmación de la dignidad a partir de modos de humillación y daño personal. La protección de la integridad es imperativa y se la entiende en virtud de los atentados cometidos contra las personas que minimizan su arraigo y pertenencia a la sociedad y deslegitiman la cultura a la cual aporta y de la cual se beneficia (pp. 78-79). El prójimo se muestra en su desgracia, en las humillaciones y rebajamientos que las personas sufren. El imperativo es el cuidado y auxilio que coadyuvan a sacar a la persona despreciada de esa anulación ${ }^{14}, \mathrm{y}$, por ende, se afirma su valor o dignidad que obliga a la salvaguarda, actitud ésta la del samaritano.

Los cuidados y los auxilios son acciones compasivas. De ahí que la medicina paliativa tenga tanta aceptación en nuestros hospitales. Abundan en el campo de la salud las experiencias que expresan anulación de sí, de desequilibrio, de resquebrajamiento de las condiciones de vida ${ }^{15}$. Al igual que el infortunio del hombre que auxilió el samaritano, la experiencia del dolor se torna elocuente y una interlocución legítima es la respuesta de solidaridad y sostén, de profesionales y familiares. Es una experiencia que requiere de sentido y valor con miras a la capacidad de resistencia de los pacientes. La misericordia, por tanto, reivindica que la persona infortunada pueda salir de su despojamiento.

\section{3. ¿Quién se compadece?}

El prójimo es el extraño con el cual hay acercamiento, y fue el samaritano el único que no dio un rodeo cuando lo encontró. En lugar de alejarse, se aproximó, le hizo su prójimo sin conocerle, sin tener familiaridad ni nacionalidad común. Los otros dos hombres, conocedores de la Ley, no vieron ningún compromiso con el hombre infortunado, se alejaron, se sustrajeron a la proximidad con el hombre en desgracia. «La proximidad del otro es [...] el hecho de que el otro no es próximo a mí simplemente en el espacio, o allegado como un pariente, sino que se aproxima esencialmente a mí en tanto yo me siento -en tanto yo soy- responsable de él» (Lévinas, p. 90). El reconocimiento y la interpelación son posibles por la atención puesta en la persona sufriente: volver la mirada y exponerse a una realidad que nunca es sólo ajena y que es comprendida como una distorsión de la existencia aceptable.

De un hombre de un pueblo impuro proviene la compasión. Él y el herido tienen una común experiencia del desprecio ${ }^{16}$. Los une una herida. Por otra parte, el texto evangélico muestra el papel que pueden jugar las mediaciones en la conducta ética. ¿Quién resulta ser en el relato el más calificado para ser compasivo? La respuesta atañe a las diferencias y alejamientos que provocan la extrañeza. En primera instancia, la cercanía no faculta a la compasión ${ }^{17}$ : el sacerdote y el levita no vieron por qué auxiliar al coterráneo en desgracia. Al contrario, el samaritano no concibe no detenerse y dar su ayuda. Por encima de esas mediaciones simbólicas el samaritano sabe responder a las exigencias de la situación. Saber responder indica varios significados: reconocer al hombre en desgracia, ver su compromiso (lo que le debía) y las acciones que se siguen del reconocimiento, también es notar lo inadmisible de la desgracia y determinar la restauración de la vida herida y de los tejidos 
sociales rotos. Las acciones son siempre concretas, amasadas con las circunstancias y ligadas a la convivencia, a los estilos de vida legitimados y marginados. Por consiguiente, la compasión del samaritano no vale como un acto aislado, sino como anclado en su sociedad. Su auxilio es una estimación - aprecio- de la vida que no permite a nadie perderla o minimizarla. En virtud de ello reconoce al otro como la mano ajena que es próxima. Al igual que auxiliar implica una exigencia preferible de evadir, así admitir la insuficiencia y la dependencia no es sencilla. Mas acepta el auxilio. Los respaldos culturales no interfieren en las correlaciones dialógicas que se abren con el acercamiento, los extraños morales también se entienden y conviven.

\section{4. ¿Qué obliga?}

Lo ético no se nutre primeramente de las experiencias positivas que impliquen compromisos significativos con los demás ${ }^{18}$. Son las experiencias del desprecio y del dolor las que detonan la dimensión ética.

La compasión o misericordia pone de manifiesto la diferencia entre el compadecido y el compasivo. Están en situaciones distintas. Uno necesita del otro. La finalidad es levantar a aquel cuya vida ha sido minimizada. El hombre en desgracia ha expuesto su fragilidad y su cercanía con la muerte. Y para el samaritano, quien vive socialmente excluido ${ }^{19}$, comparte con el compadecido el desprecio, experiencia común con la cual se establecen puentes de comunión, de re-afirmación y reconocimiento. Si la ofensa y la marginación son formas de intersubjetividad que destruyen la confianza en sí (la autosuficiencia del hombre en desgracia ha sido invalidada por la expropiación de la cual ha sido objeto) y en el otro (ser asaltado y evadido restan credibilidad a la sociedad en la cual vive), asimismo estas formas de desprecio se tra- ducen en vías por las cuales reconstruir la dignidad alienada. Para el samaritano, la diferencia de condiciones se transmuta en aproximación y comunión: hace suyas las desgracias ajenas, las asume como responsabilidad inmediata -el infortunio ajeno apremia ${ }^{20}$ - . Lo común a ambos es la vida contingente, saberse frágiles y mortales, víctimas de una exclusión, por encima de ser extraños el uno para el otro. La distancia entre el infortunado y el samaritano se acorta en virtud de esta condición compartida. Como parte de lo que venimos diciendo, la aproximación en la relación clínica ha de considerar varias posibilidades y no solamente la de la enfermedad, admitida e impuesta.

La respuesta dada al final del relato es una afirmación del reconocimiento: el otro interpela, cuestiona y devela la finitud de la vida humana. «Rostro y discurso están ligados. El rostro [del otro] habla. [...] el discurso, y más exactamente, la respuesta o la responsabilidad es esa relación auténtica» (Lévinas, p. 82). Precisamente este reconocimiento introduce en una dimensión de acercamiento que no se divisa por las diferencias que mantienen distantes a las personas. Y posiblemente ello actuó en el sacerdote y el levita que esquivan al infortunado.

Las pretensiones del compasivo de salvar a la persona desdichada, persiguen para sí lo mismo en tanto ambos comparten una misma condición. «El piadoso o el amante no quieren salvar solamente al otro compadecido o amado, sino salvarse los dos a la vez, no postergan esa salvación a otra vida futura, sino que la buscan empeñadamente en ésta» (Arteta, p. 256). Esta constatación no deja de ser una nota sobre el egoísmo que opera al rescatar la vida del otro: no quiero pasar por ese mismo peligro, no quiero morir. El instinto de autoconservación, advertido por Hobbes, no ha dejado de animar la convivencia. No obstante, ello no permite concluir que la compasión es una actitud que, en el fondo, 
vela por la preservación de la propia existencia. La vida del otro priva aun en aquellos casos en que la propia sufra algún daño.

El reconocimiento, entonces, corre en dos direcciones y comporta un mismo significado fundamental: la existencia contingente de todos y las acepciones que se deriven relativas al desprecio vivido por las personas en desgracia. "De ahí que la relación de reconocimiento que corresponde a esta forma de desprecio sea la que pueda ayudar al individuo a una autoestima de este tipo, una relación de aprobación solidaria para formas de vida alternativas; en esta relación encontrarían los sujetos, con sus características individuales, como personas individualizadas a lo largo de su biografía personal, el reconocimiento recíprocamente alentador» (Honneth, p. 86).

La pregunta inicial del relato se respalda en una preocupación ética —quién requiere de mí- y la respuesta apunta al criterio y a la indicación práctica. La compasión es el resultado de una interpelación, para la cual basta la desgracia del otro que es o puede ser la mía, mas pareciera que ello no es evidente, el mal o sufrimiento ajeno no es a priori un móvil ineludible de respuestas. Se hace necesario, entonces, hacerlo consciente, aprender a reconocer al otro en su desdicha y a descubrirla como condición compartida —a mí también me corresponde-. Momento coactivo este que deviene luego del reconocimiento del infortunio del otro. Pero también es un momento pedagógico: desarrollar una capacidad para reconocer al prójimo. Es igualmente un momento prescriptivo, agravado por el inconveniente de la universalización para la vida ética: ¿cómo es posible extenderla a todos los hombres y mujeres? ¿Es posible normar la compasión?

Los intentos de respuesta compasiva que se esbocen han de tener presente que el reconocimiento del otro es una forma de autocomprensión y de afirmación de la fragilidad de la existencia humana que clama por protección y humanización, o en términos de salud, de tratamientos, cuidado y atención, así como de percepciones éticas que no se elaboren con base en el divorcio entre los signos y síntomas mórbidos y el sujeto de los mismos. Percepciones de la vida y la muerte, del dolor y de la salud que corren juntas y son vividas en una sola amalgama.

Asimismo, la universalización de la compasión sólo sería posible no a partir de una prescripción «ciega», sino del involucramiento de todos los seres humanos en virtud de la fragilidad y miseria originarias que comparten biográficamente. La apelación a la conciencia de las personas parece el único camino viable, mas no es sencillo.

No se nace compasivo, como no se nace virtuoso. Ante la desgracia del otro siempre hay un sentimiento de conmiseración que remueve las entrañas, pero, «la sensibilización es sólo epidérmica» (Innerarity, p. 194), y la indiferencia fácilmente se alimenta de reacciones emotivas que bien agravarían más la desgracia de las personas enajenadas o desvirtuarían los compromisos. No, no es ésta la compasión a la cual se refiere el texto bíblico, ni es ésa la prescripción ni el carácter que le acompañan. Tenían razón los estoicos y Nietzsche al rechazar la debilidad de la reacción emotiva ante el dolor ajeno. La fortaleza ética que reclama la compasión dista mucho del simple contagio por el dolor de la persona en desgracia.

Bien sea que se considere la compasión una actitud que los individuos desarrollan o una virtud que consistiría en una cualidad humana adquirida, queda en claro que no se posee, aunque puede admitirse una disposición para la compasión. La adquisición no significa una apropiación «desde fuera» de las personas, a modo de una cualidad que se suma al talante ético, sino que es el resultado de un esfuerzo racional y afectivo. 
Es a través del ejercicio de la compasión que se llega a ser compasivo y por medio de la compasión se sabe quién es el prójimo. La paradoja reside en el hecho de la desgracia y miseria del otro para su cultivo. Su sustento racional y afectivo la anima con las situaciones que muestran dilemas, el caso de la eutanasia. Hay que hablar entonces de una compasión que sea fruto de una educación racional, que requiere del ejercicio de las disposiciones a la acción. «De este hecho resulta claro que ninguna de las virtudes éticas se produce en nosotros por naturaleza, puesto que ninguna cosa que existe por naturaleza se modifica por costumbre» (Aristóteles, II, 1103. a , 15).

Estos desarrollos relativos a la compasión constituyen una percepción de lo ético. Dónde se colocan y si constituyen una fundamentación de la ética, poco puede decirse en esta ocasión. Es una especulación que obedecería a otros propósitos. Pero al menos puede alegarse que se mira a la compasión como hendida en la experiencia común de la fragilidad, es comunicable y articuladora de la intersubjetividad, en términos positivos y negativos. La compasión habla a la teoría ética de una experiencia biográfica que es universalizable sólo en cuanto experiencia: vemos la desgracia ajena en distintas situaciones y con distintos sujetos. Ello afecta la autopercepción y la percepción del otro, con el «descubrimiento» de la fragilidad de la existencia humana, exclusiva de todo ser humano y de amplio y variopinto espectro. Para efectos de lo que aquí interesa, y que cuenta con sitios específicos en los cuales se expresa a sus anchas, es el caso de los hospitales y clínicas. Su racionalidad reside en ese reconocimiento y en la dilucidación de caminos por los cuales ganarle la partida a la desgracia $\mathrm{y}$ al sufrimiento.

\section{CONCLUSIONES: \\ ¿QUÉ RESULTA DE ESTE ENSAYO SOBRE LA COMPASIÓN?}

La práctica clínica es una realidad altamente exigente, mucho se espera de sus profesionales y también mucho han de sufrir usuarios y pacientes para recuperar la salud perdida o quebrantada. Resulta una preocupación permanente cuál es el modelo de conducta más conveniente para tratar a pacientes y usuarios, para convivir con profesionales afines. La compasión que aquí hemos esbozado ofrece algunas iniciativas para una percepción de lo ético que privilegie la protección de la vida y su alejamiento de las amenazas de peligro y deterioro - mayor aún- que puedan sufrir adicionalmente a sus disfunciones, en virtud de la interacción institucional y por terapias y procedimientos médico-quirúrgicos a los que se vean sometidos. Hospitales y profesionales son extraños, no ofrecen bastión alguno con el cual elaborar arraigos que permitan hacer soportable su estadía y las dificultades fisiológicas que padecen. La compasión se puede confundir con una actitud lastimera o con esa arrogancia que da de disponer del saber que cura. Pero sabemos que bien poco contribuye esa compasión a que la vida del otro no se pierda. Tal vez ni siquiera haya una preocupación genuina por la vida del otro. Y de esta manera es comprensible la constatación cotidiana del estudiante de medicina que expresa las dificultades que ha pasado para despojarse de la compasión para el ejercicio profesional. De acuerdo con lo que hemos afirmado, es necesaria una estimativa por la cual reconocer una compasión legítima.

La bioética, modestamente, ha asegurado un sitio para la compasión en el principio de beneficencia. Es imposible para cualquier profesional de la salud dejar de perseguir el bienestar de sus pacientes y evitarles todo daño. Es este principio una garantía suficiente para promover la com- 
pasión como esa exigencia de excelencia a la que cualquiera está invitado a adoptar. Queda abierta, entonces, una percepción de lo ético cuyo asiento es la intersubjetividad: reconocimiento de la desgracia ajena y esfuerzo por liberar al otro de sus miserias. Dos momentos por los cuales se articula la compasión, una iniciativa que sólo se explica dialécticamente, la existencia que sólo se puede realizar por el concurso de unos y otros.

La constatación cognitiva no es «suficiente» justificación para ser compasivo, ¿por qué he de serlo? Sin embargo, apelamos en esta ocasión a la imposibilidad de la indiferencia o de otras justificaciones éticas ante la desgracia de aquellos que por razones fisiológicas o de otro orden han sufrido una disminución en sus vidas y no hacer nada por ellos. ¿De qué manera, entonces, se hace la vida humana? En el mundo que vivimos, hay una premura por hacer lo que podamos por gozar todos, no sólo unos, de una vida buena, de una existencia que signifique oportunidades garantizadas, libre de prácticas de exclusión y que signifiquen una afirmación valórica y fáctica de la vida: cada quien merece vivir y lograr lo mejor de sí. En esos términos se cifra la compasión.

La parábola evangélica es un símbolo del cual nos servimos para estimular la reflexión acerca de la compasión y su conexión con el mundo de la salud. Sin embargo, sus contenidos muestran una significación compleja que no hemos agotado. Tan sólo piénsese en la actitud compleja que esboza: interdependencia, responsabilidad, compromisos, cuidados, vida institucional. Y a todo ello el hagiógrafo le llama misericordia. De acuerdo con López de la Vieja, ese conjunto «actitudinal» sigue otro punto de vista y «se convierte en un modo característico de resolver los dilemas morales» (2000a, p. 65), que acentúa el aspecto relacional de la convivencia. Cuidado y compasión tienden a lo mismo: recuperar la existencia disminuida o daña- da. Sin embargo, mientras que el primero apela a acciones concretas, articuladas con miras al bienestar del paciente, la compasión se dirige a la actitud o virtud que acompaña al sujeto que da el cuidado. Pero es posible ser compasivo sin tener responsabilidades de cuidado, y éstas a su vez pueden darse sin compasión. "Aunque el cuidado es usualmente desarrollado durante el tratamiento, también conlleva una actitud de empatía focalizada en el bienestar de aquellos que experimentan una etapa en sus vidas particularmente vulnerable» (Sabatino, p. 375).

\section{BIBLIOGRAFÍA CONSULTADA}

Abbagnano, Nicolá: Diccionario de Filo-

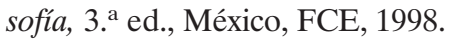

Aquino, Tomás de: Suma Teológica, Madrid, BAC, 1997.

Arteta, Aurelio: La compasión. Apología de una virtud bajo sospecha, Barcelona, Paidós Ibérica, 1996.

Beauchamp, T., y Childress, J.: Principles of biomedical ethics, 5. ${ }^{\text {a }}$ ed., Oxford, Oxford University Press, 2001.

CAmps, Victoria: Una vida de calidad. Reflexiones sobre bioética, Barcelona, Ares y Mares, Crítica, 2001.

Careaga, G.; Figueroa, J., y Mejía, M. a Ética y Salud Reproductiva, México, PUIS, Porrúa, 1996.

Gracia, Diego: Fundamentos de Bioética, Barcelona, Ariel, 1997.

- Fundamentación y enseñanza de la bioética, 2. ${ }^{a}$ ed., Bogotá, DC, El Búho, 2000.

Guariglia, Osvaldo: Cuestiones Morales, Madrid, Trotta, 1996.

Honneth, Axel: «Integridad y desprecio. Motivos básicos de una concepción de la moral desde la teoría del reconocimiento», en Isegoría, núm. 5, Madrid, 1992, pp. 78-92.

INNERARITY, Daniel: Ética de la hospitalidad, Barcelona, Península, 2001. 
KAnT, Emmanuel: Fundamentación de la metafísica de las costumbres, 14. ${ }^{\mathrm{a}}$ ed., Madrid, Espasa Calpe, edición Luis Martínez de Velasco, 1999.

LADRIÈRE, Jean: «El sentido de la bioética», en Acta Bioethica, año VI, núm. 2, 2000, pp. 197-218.

LÉvinas, Emmanuel: Ética e infinito, Madrid, Visor, 1991.

LolAs, Fernando (ed.): Bioética y cuidado de la salud. Equidad, calidad, derechos, OPS-OMS, Programa Regional de Bioética, 2000.

LÓPEZ dE LA VIEJA, M. ${ }^{\text {a }}$ Teresa (ed.): Feminismo del pasado al presente, Salamanca, Ediciones Universidad de Salamanca, 2000a.

- Principios morales y casos prácticos, Madrid, Tecnos, 2000b.

MARLASCA, Antonio: Introducción a la bioética, Heredia: Facultad de Filosofía y Letras, Universidad Nacional, 2001.

McIntyre, Alasdair: After virtue, 2. a ed., Notre Dame, University of Notre Dame Press, 1984.

Organización Panamericana de la Salud: Bioética: temas y perspectivas, Washington, DC, OPS-OMS, 1990.
SABAtino, Charles: «Reflections on the Meaning of Care», en Nursing Ethics, 6 (5), 1999, pp. 374-382.

SAVATER, Fernando: Invitación a la ética, Barcelona, Anagrama, 1995.

SCAvone, Lucila (comp.): Género y salud reproductiva en América Latina, Cartago, Libro Universitario Regional, 1999.

SeINOZA, Baruj.: Ética demostrada según el orden geométrico, Madrid, Trotta, edición de Atilano Domínguez, 2000.

Sumner, L. W., y Boyle, Joseph: Philosophical perspectives on Bioethics, Toronto, University of Toronto Press, 1996.

Tajer, D.; Ynoub, R., y Huggins, M. (comps.): Género y salud colectiva, Asociación Latinoamericana de Medicina Social, 1998.

TucketT, Anthony: «Nursing practice: compassionate deception and the Good Samaritan», en Nursing Ethics, 6 (5), 1999, pp. 383-389.

Vidal, Marciano: Cuestiones actuales de bioética, San José, Eidos, 1998.

\footnotetext{
${ }^{1}$ La historia del señor $\mathrm{N}$. fue relatada en un curso universitario por el paramédico que labora en dicho hogar de ancianos y se ocupó de llevar al señor al hospital y bregar por que fuera atendido.

2 Cf. López de la Vieja, 2000a, pp. 61-66.

${ }^{3}$ La información aquí consignada es tomada del sitio respectivo de la red informática internacional. La dirección para cualquier consulta es la siguiente: http://www.justice4diane.org.uk

${ }^{4}$ Para tener conocimiento del relato de Karen Ann Quinlan, consultamos en la red informática internacional el sitio correspondiente a la situación vivida por ella y su familia. La dirección es http://www.csulb.edu/javacamp/452 r6.html

${ }^{5}$ Acerca de Ramón Sampedro se consultó la carta que él mismo dirigió a los jueces. El documento está disponible en el sitio http://www.eutanasia.ws/car-

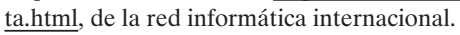

${ }^{6}$ José M. G. Gómez-Heras, El a priori del mundo de la vida: fundamentación fenomenológica de una ética de la ciencia y de la técnica, Barcelona, Anthropos, 1989; Hans Blumenberg, Las realidades en que vivimos, Barcelona, Paidós, 1999; Jürgen Habermas, «Edmund Husserl sobre mundo de la vida, filosofía y ciencia», en Textos y contextos, Barcelona, Ariel, 1997.

${ }^{7}$ Aristóteles, Retòrica, 1385 b a 1386 b, siguiendo esta definición, que es suya, explica quiénes pueden sentir compasión, de quiénes, y de qué.

${ }^{8}$ Sobre estas tradiciones, véase Abbagnano, Diccionario de Filosofía. El artículo correspondiente no toma en cuenta a Kant, quien en la Fundamentación de una metafísica de las costumbres parte de la definición aristotélica para mostrar una aplicación del imperativo categórico.

9 Misericordia y compasión designan la misma actitud, a pesar de que el primer término se inscribe en una semántica religiosa y el segundo no. Entrevemos 
en estos términos una actitud entrañable y una solidaridad sostenida con quienes requieren auxilio.

10 «La excelencia [...] es más que cumplir rígidas reglas y principios, de manera acrítica...» (Tuckett, p. 386).

${ }^{11}$ No olvidemos que la bioética se ocupa de tener claros principios o normas, y procedimientos adecuados para resolver o esclarecer casos difíciles y conflictos. En ese sentido, es obligatorio colocarse más allá de ella, en el plano ético que prevalece para el mundo de la vida.

${ }^{12}$ Hay quienes señalan una relación conflictiva entre el cuidado y los tratamientos, en la que éstos pueden tener más peso y tomar más tiempo que aquél. "Desafortunadamente, muchas enfermeras reclaman que el sistema de salud, con una sofisticación cada vez mayor para el tratamiento de disfunciones y enfermedades, puede no permitirle a las personas encargadas del cuidado de gozar el tiempo necesario para responder con toda la sensibilidad requerida para el cuidado» (Sabatino, p. 375). Creemos que más allá de dos percepciones éticas, hay dos concepciones de salud, vida y muerte acuñadas en forma de saberes autorizados que pernean y organizan las prácticas sanitarias.

13 «La investigación realizada por C. Gilligan demostró que la experiencia de las mujeres crea la impresión de un desarrollo moral desviado o deficiente, cuando sólo se aplica el modelo de L. Kohlberg». «Ser mujer parecía un auténtico impedimento para ser o para pensar como un adulto» (López, 2000a, p. 63).
${ }_{14}$ «A la cosa de la que nos compadecemos, nos esforzaremos cuanto podemos en librarla de la miseria» (Spinoza, Ética, 3/27c3).

15 «Todo dolor, incluso el más leve, nos revela nuestra impotencia y nuestra fragilidad, no tan sólo altera la relación del hombre con su cuerpo, sino que invade más allá: contamina la relación total del hombre con su mundo» (Bustos, p. 109).

${ }_{16}$ Honneth entiende el desprecio como «aquel aspecto de una conducta dañina por el que las personas son heridas en la comprensión positiva de sí mismas que han adquirido por vías intersubjetivas» (p. 80).

${ }^{17}$ Sin embargo, Santo Tomás de Aquino habla de la condolencia con el amigo infortunado. «La amistad se manifiesta en uno y otro caso, esto es, alegrándose con el que se alegra y condoliéndose con el afligido» (S. Th. I, Ia-IIae, c. 38, art. 3, ad primum). Y Spinoza no distingue entre conocidos y desconocidos al hablar de la compasión.

18 «... no es en fuentes positivas de motivación, como el altruismo o el respeto, donde la moral puede encontrar un apoyo práctico dentro de la realidad social, sino en la experiencia del desprecio social, experiencia que se presenta espontánea y reiteradamente» (Honneth, p. 87).

19 A. Honneth, al hablar de la autocomprensión normativa de las personas, sugiere que «ello alude a tipos de desprecio personal que se causan a un sujeto de manera que quede estructuralmente excluido de la posesión de determinados derechos dentro de una sociedad» (p. 81).

${ }^{20}$ Cfr. Lévinas, pp. 89-96. 